\title{
Article \\ Hardware Reliability Analysis of a Coal Mine Gas Monitoring System Based on Fuzzy-FTA
}

\author{
Jingtian $\mathrm{Xu}{ }^{1} * *$ CD Man Yang ${ }^{1}$ and Shugang $\mathrm{Li}^{2}$ \\ 1 School of Electronic Engineering, Xi'an Shiyou University, Xi'an 710065, China; \\ 20212030440@stumail.xsyu.edu.cn \\ 2 School of Safety Engineering, Xi'an University of Science and Technology, Xi'an 710065, China; \\ lisg@xust.edu.cn \\ * Correspondence: jtxu@xsyu.edu.cn; Tel.: +86-1357-2255334
}

check for updates

Citation: Xu, J.; Yang, M.; Li, S

Hardware Reliability Analysis of a Coal Mine Gas Monitoring System Based on Fuzzy-FTA. Appl. Sci. 2021, 11, 10616. https://doi.org/10.3390/ app112210616

Academic Editors: Jordi Cusido and Radu Godina

Received: 11 October 2021

Accepted: 9 November 2021

Published: 11 November 2021

Publisher's Note: MDPI stays neutral with regard to jurisdictional claims in published maps and institutional affiliations.

Copyright: (C) 2021 by the authors Licensee MDPI, Basel, Switzerland. This article is an open access article distributed under the terms and conditions of the Creative Commons Attribution (CC BY) license (https:// creativecommons.org/licenses/by/ $4.0 /)$.
Featured Application: This project is applied on the computer monitoring project of the coal mine gas monitoring system in Shaanxi, China.

\begin{abstract}
The hardware reliability of a gas monitoring system was investigated using the fuzzy fault tree analysis method. A fault tree was developed considering the hardware failure of the gas monitoring system as a top event. Two minimum path sets were achieved through qualitative analysis using the ascending method. The concept of fuzzy number of the fuzzy set theory was applied to describe the probability of basic event occurrence in the fault tree, and the fuzzy failure probabilities of the middle and top events were calculated using fuzzy AND and OR operators. The results show that the proposed fuzzy fault tree is an effective method of reliability analysis for gas monitoring systems. Results of calculations using this method are more reasonable than those obtained with the conventional fault tree method.
\end{abstract}

Keywords: fuzzy; FTA; gas; reliability; monitoring system

\section{Introduction}

Coal mine gas monitoring systems play an important role in improving the safety of China's coal mines, reducing personnel and property losses, and improving the production efficiency and modernization level of the mines. However, in recent years, gas accidents (especially serious and extremely serious gas explosion accidents) have occurred frequently even in coal mines equipped with mine gas monitoring systems, resulting in many casualties and heavy losses. Therefore, in order to ensure the reliable operation of the coal mine gas monitoring system, the reliability analysis of the gas monitoring system is extremely important.

At present, the reliability analysis of the gas monitoring system mainly uses evaluation methods such as the fault tree analysis (FTA), pre-hazard analysis method, and safety checklist method for analysis. However, the results obtained are quite different from the actual field. At present, researchers are adopting some new theories. For example, the analytic hierarchy process [1], cloud model evaluation method, extension theory [2], quantitative improvement HAZOP, etc. are applied to the reliability analysis of the gas monitoring system [3]. The main problem encountered by these new methods in reliability analysis is the need for a large amount of precise and accurate data. However, in the field of gas monitoring systems, it is difficult to obtain the accurate probability value of the occurrence of basic events. Generally, mines do not have long-term unified equipment failure record data. Due to the fact that the sample size is too small, the value cannot be used as an accurate probability value that requires a large sample size. In order to solve the problem that there is no accurate data and only fuzzy data in the gas monitoring system, 
this paper uses the fuzzy fault tree analysis method that combines fuzzy mathematics and fault tree analysis to analyze the hardware reliability of the gas monitoring system.

The research of the fuzzy fault tree analysis began with scholars such as Tanaka $\mathrm{H}$ et al. [4]. They realized that the probability of the bottom event and top event in a fault tree is often not a fixed value, and it has a certain degree of ambiguity. In this case, they first proposed the replacement of the fixed probability of events in the fault tree with the fuzzy probability. In addition, they described the fuzzy probability of each bottom event in the system with a fuzzy number according to the fuzzy algorithm, in which the fuzzy number replaces the traditional accurate value and approximate value. Huang et al. proposed a fuzzy analysis method of the fault tree in the machining system, and actually constructed a fault tree in the machining system [5]. Li Qing et al. introduced the generalized maximum and minimum method in the fuzzy fault tree analysis [6], which defined the fuzzy number as a triangular distribution to calculate the probability distribution of the occurrence of the bottom event. Liu Puyin et al. further used the triangular fuzzy numbers to stipulate fuzzy numbers for the analysis and research [7], and proposed a new analysis method for the importance of bottom events. Zhang Yuqing et al. constructed a complete fault tree of the hydraulic system of the water jet propulsion using the fuzzy fault tree analysis method [8], and finally obtained the probability interval of the occurrence of the top event. Liu Shaohui et al. used fuzzy numbers rather than an accurate probability to deal with uncertain problems [9], which reduced the difficulty of obtaining the accurate value of event probability. Singer et al. used the L-R fuzzy number to define the probability of the bottom event for the first time [10], and provided the probability calculation method under the L-R fuzzy number. Sawyer et al. constructed a fault tree for a simple system [11], combined with a fuzzy algorithm to take the probability of the bottom event as a fuzzy number, and then took the $\lambda$ cut set to obtain the probability of the top event. Misra and Weber used a discrete method to discretize the membership function of the bottom event [12], then used the fuzzy expansion principle and fuzzy operator to calculate the interval, and finally obtained the probability of the top event. Kenarangui et al. used the fuzzy probability to analyze the event tree [13]. The event tree is a dual form of the fault tree. Moreover, their conclusions bring certain significance to the study of the fault tree. Furuta et al. extended the concept of traditional importance and used the fuzzy integral to provide a new fuzzy importance, then applied it to the actual reliability engineering [14].

This article intends to use the fuzzy fault tree analysis method to analyze the various conditions of the coal mine gas monitoring system failure [15], in order to achieve the following purposes: (1) Identify the basic events and human errors that lead to gas monitoring system accidents; (2) provide clues to avoid the basic causes of accidents, in order to reduce the possibility of accidents; (3) make a comprehensive, concise, and vivid description of the various factors and logical relations leading to disasters and accidents; (4) identify all kinds of inherent or potential risk factors in the system and provide a scientific basis for design, construction, and management; (5) make the relevant personnel and operators fully understand and master the key points of disaster prevention; (6) produce a qualitative and quantitative analysis and systematic evaluation of the safe operation of coal mine gas monitoring systems.

\section{The Principle of the Fuzzy-FTA Analysis}

\subsection{Fault Tree Analysis Method Process}

The fault tree analysis is a graphical analysis method of causality and logical relationship that finds the various factors related to the disaster accident from the result to the cause. This method is used to analysis what may happen in the system. Therefore, it is placed at the top of the graph and is called the top event. According to the relationship between the elements of the system, the causes related to disasters and accidents are analyzed. These reasons may be the result of other reasons, called the intermediate cause event (or intermediate event), and should continue to be analyzed until the reasons cannot be analyzed further. These reasons are called the basic cause event (or basic event). The 
causal relationships in the figure are connected by different logic gates to get an image of an upside-down tree.

The basic procedure of the FTA method is shown in Figure 1. The first step is to get familiar with the system that needs to be analyzed, by understanding the system status and various parameters, and drawing the process flow chart or floor plan. Second, the information on the accident cases (which occurred in the same industry and on similar devices at home and abroad) is collected, and the accidents that have serious consequences and can easily occur as top events are identified. Based on the experiences, lessons, and accident cases, after the statistical analysis, the probability (frequency) of the accident is calculated, and the target value of the accident to be controlled is determined. Then, the fault tree is constructed from the top event according to the logical relationships among the events. If the constructed fault tree does not conform to the on-site conditions, it is also necessary to collect the missing information, re-analyze system failures and abnormalities, until the established fault tree is in line with the actual on-site conditions. Finally, a qualitative analysis is performed to determine the structural importance of each basic event, the probability is calculated, and a quantitative analysis is performed.

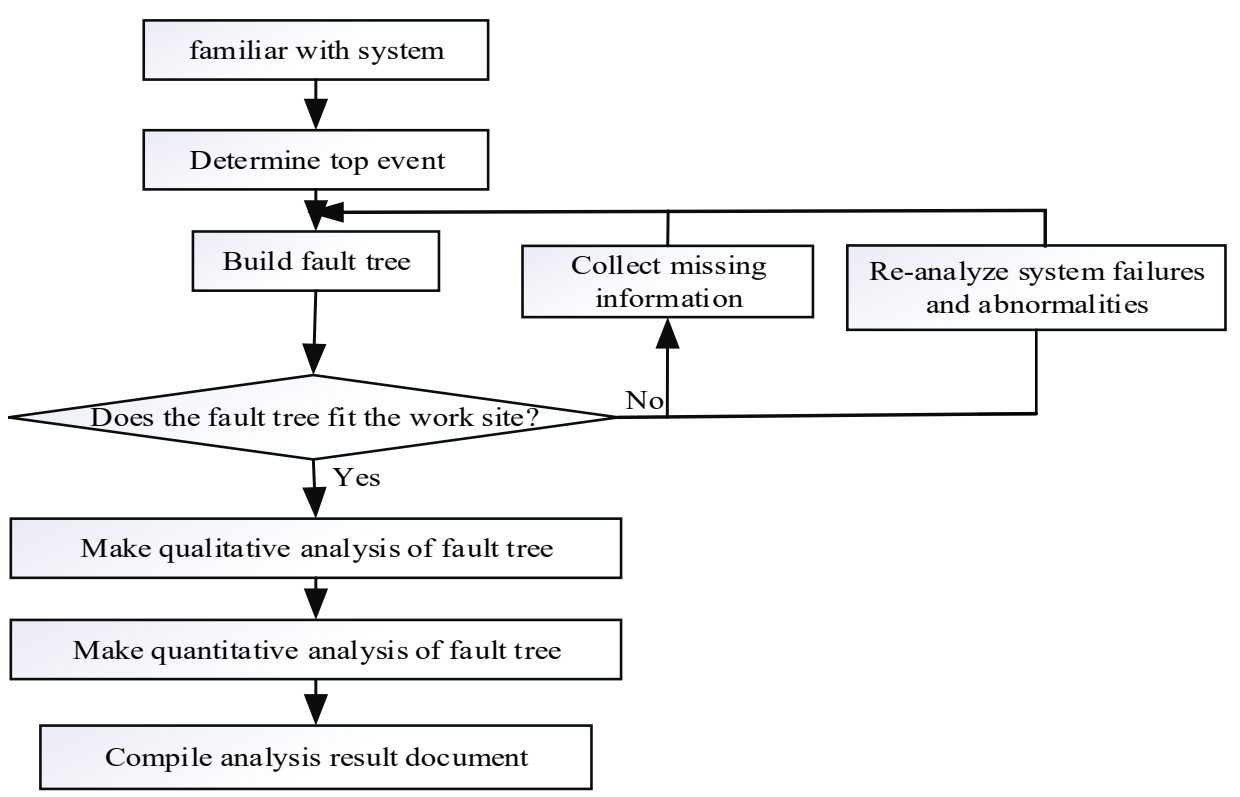

Figure 1. Workflow of the FTA method.

(1) Construction of the fault tree

The construction of the fault tree starts from the top event. The direct, indirect, necessary, and sufficient causes of the top event are determined by deduction and reasoning. Usually, these reasons are not basic events but intermediate events that need further development.

(2) Qualitative analysis of the fault tree

The qualitative analysis is based only on the structure of the fault tree and the causal relationships of the events leading to the accident. The analysis includes finding the minimum cut set, the minimum path set, and the structural importance of basic events.

(3) Quantitative analysis of the fault tree

The purpose of this analysis is to calculate the occurrence probability of the top event and evaluate the safety and reliability of the system. Specifically, the method consists of comparing the calculated probability of the top event with the predetermined target value. If the latter is exceeded, the necessary system improvement measures should be taken to reduce it below the target value. 
(4) Preparation of documentation on the results

The final step is to compile the result file. The analyst should provide the description of the analysis system, a discussion of the problems, the fault tree model itself, the minimum cut set, the minimum path set, and the structural importance analysis. Moreover, the analyst should give relevant conclusions for the fault tree analysis of coal mine gas monitoring system.

The main principles of the Fuzzy-FTA method are as follows. Although the data recorded on site are insufficient, managers and experts with rich experience in the front line have a relatively accurate perceptual grasp of the failure probability. Therefore, confidence intervals for the occurrence of basic events can be estimated by analyzing the responses to the questionnaires administered to them. Then, through the qualitative analysis of the FTA method, the confidence interval of the occurrence probability of top events is obtained at a certain confidence level. In summary, the Fuzzy-FTA analysis method is found capable of qualitatively and quantitatively analyzing the reliability of a gas monitoring system hardware and calculating its failure probability [16].

\subsection{Basic Principles of Fuzzy Mathematics}

\subsubsection{Fuzzy Set and Membership Degree}

Definition: Set on the universe $U$, specify a mapping for any $x \in U, \mu_{A} \rightarrow[0,1]$, existence:

$$
\mu \mid \rightarrow \mu_{\underline{A}}(\mu) \rightarrow[0,1]
$$

where $\mu_{A}(\mu)$ is the membership degree $\underline{A}$ of a set (or the membership degree of $\underline{A}$ ), and the mapping is a membership function of a set $\underline{A}$. When the membership degree can only assume the values 0 or 1 , the fuzzy set degenerates into a classical set.

\subsection{2. $\lambda$. Cut Sets}

Definition: Set up $A \in F(U)$, find any $\lambda \epsilon[0.1]$, record:

$$
\mu_{\lambda}=\{\mu \in U \mid A(\mu) \geq \lambda\}
$$

where $A_{\lambda}$ is the $\lambda$ cut set of $A$, and $\lambda$ is the threshold or confidence level. If $\lambda$ is within [0, $1]$, the classical set family in $U$ is obtained. When a certain level $\lambda$ is given, the fuzzy set $\mathrm{A}$ is refined to $A_{\lambda}$.

\subsubsection{Fuzzy Numbers and Their Properties}

If you want to blur a crisp number, there are generally two ways, which are to express the crisp number as an interval fuzzy number or a triangular fuzzy number. In fact, the concepts of triangular fuzzy numbers and interval fuzzy numbers are generalizations of the crisp numbers. Moreover, the concept of triangular fuzzy numbers is an extension of the concept of interval fuzzy numbers. However, compared with those of intervals, the operational laws of triangular fuzzy numbers are more mature and easier to use. Therefore, this paper chose the triangular fuzzy number to blur the precise number.

A triangular fuzzy number consists of three numbers, including the minimum membership degree, the medium membership degree, and the maximum membership degree. In any situation of subjective decision making, this triple number can be respectively regarded as the lower (conservative), the medium, and the upper (optimistic) estimation with regards to a judgment.

Definition 1. The fuzzy number $A_{\lambda}$ is a continuous fuzzy subset of universe $R$ on $(-\infty,+\infty)$, and its convex membership fuzzy function satisfies

$$
\max _{x \rightarrow R} \mu_{A(x)}=1
$$


Definition 2. $L, R$ is the reference function of a fuzzy number if

$$
\mu_{\sim}(x)=\left\{\begin{array}{cc}
L\left(\frac{m-x}{a}\right) & \text { when } x \leq m, a>0 ; \\
R\left(\frac{m-x}{\beta}\right) & \text { when } x>m, \beta>0 ;
\end{array}\right\}
$$

Then, the fuzzy number is renamed as the $L-R$ fuzzy number and recorded as $\underline{A}=$ $(m, \alpha, \beta)$, where $m$ is the average of a and $(\alpha, \beta)$ is the upper and lower confidence limit of $\underline{A}$. $\underline{A}$ is not a fuzzy number when $\alpha, \beta$ are both 0 . $\underline{A}$ is fuzzier when the distribution of $\alpha, \beta$ is large.

$$
\underline{A}=(m, \alpha, \beta)_{\mathrm{LR}}
$$

If a triangular fuzzy number, $\underline{A}=[(m-\alpha)+\alpha \lambda,(m+\beta)-\beta \lambda]$ is an interval number, according to the classical expansion principle, the following expansion formula holds:

For $\forall \lambda \in[0,1]$ :

(1) Addition:

$$
\underset{\sim \lambda}{A}+\underset{\sim \lambda}{B}=\left[L_{A}^{\lambda}, R_{A}^{\lambda}\right]+\left[L_{B}^{\lambda}, R_{B}^{\lambda}\right]=\left[L_{A}^{\lambda}+L_{B}^{\lambda}, R_{A}^{\lambda}+R_{B}^{\lambda}\right]
$$
$\mathrm{B}_{\lambda}$

Formula (6) is the addition calculation rule of two triangular fuzzy numbers $\underset{\sim \lambda}{A}$ and

(2) Subtraction:

$$
\underset{\sim \lambda}{A}-\underset{\sim \lambda}{B}=\left[L_{A}^{\lambda}, R_{A}^{\lambda}\right]-\left[L_{B}^{\lambda}, R_{B}^{\lambda}\right]=\left[L_{A}^{\lambda}-L_{B}^{\lambda}, R_{A}^{\lambda}-R_{B}^{\lambda}\right]
$$

Formula (7) is the subtraction calculation rule of two triangular fuzzy numbers $\underset{\sim \lambda}{A}$ and $\underset{\sim \lambda}{B}$. Multiplication:

$$
\underset{\sim \lambda}{A} \times \underset{\sim \lambda}{B}=\left[L_{A}^{\lambda}, R_{A}^{\lambda}\right] \times\left[L_{B}^{\lambda}, R_{B}^{\lambda}\right]=\left[L_{A}^{\lambda} \times L_{B}^{\lambda}, R_{A}^{\lambda} \times R_{B}^{\lambda}\right]
$$

Formula (8) is the multiplication calculation rule of two triangular fuzzy numbers $\underset{\sim \lambda}{A}$ and $\underset{\sim \lambda}{B}$

(3) Division:

$$
\underset{\sim \lambda}{A} \div \underset{\sim \lambda}{B}=\left[L_{A}^{\lambda}, R_{A}^{\lambda}\right] \div\left[L_{B}^{\lambda}, R_{B}^{\lambda}\right]=\left[L_{A}^{\lambda} \div L_{B}^{\lambda}, R_{A}^{\lambda} \div R_{B}^{\lambda}\right]
$$
$\underset{\lambda}{B}$

Formula (9) is the division calculation rule of two triangular fuzzy numbers $\underset{\sim \lambda}{A}$ and

\subsection{Application of the Fuzzy-FTA Method}

\subsubsection{Definition}

In Fuzzy-FTA, the fuzzy mathematics theory is introduced by:

(1) Fuzzifying the logical relationship between different levels. This indicates that when the fault tree of the system is established, the logic of each level causing the top event is not clear, but fuzzy [17];

(2) Fuzzifying the occurrence probability of basic events. This indicates the replacement of the exact value of basic events with fuzzy numbers. The fuzzy number forms of basic events mainly include normal, triangular, and ladder types [18]. 


\subsubsection{Basic Operators}

(1) AND gate fuzzy operator

If the probability of occurrence of the $i$-th basic event is a fuzzy number, which is denoted as $P_{i}$, the AND gate fuzzy operator can be denoted as:

$$
\left(P_{A N D}\right)(z)=\prod_{i=1}^{n} P_{i}=\left(P_{A N D}^{\alpha}, P_{A N D}, P_{A N D}^{\beta}\right)
$$

where $P_{A N D}^{\alpha}=\prod_{i=1}^{n}\left(m_{i}-\alpha_{i}\right), P_{A N D}=\prod_{i=1}^{n} m_{i}, P_{A N D}^{\beta}=\prod_{i=1}^{n}\left(m_{i}+\beta_{i}\right)$.

In Formula (10), if the probability of the occurrence of $n$ events is an AND relationship, then the total probability $P_{A N D}$ of the simultaneous occurrence of $n$ events is the multiplication of the probability of every occurrence of $\mathrm{n}$ events alone. $P_{A N D}$ is the total probability, $P_{i}$ is the probability of a single event occurring alone. $m_{i}$ is the mean value of the fuzzy numbers, and is specified as a real number, while $\alpha_{i}, \beta_{i}$ are the left and right extensions of the mean, respectively [19].

\section{(2) OR gate fuzzy operator}

If the probability of occurrence of basic events is a fuzzy number, then the OR gate fuzzy operator can be written as:

$$
\left(P_{O R}\right)(z)=1-\prod_{i=1}^{n}\left(1-P_{i}\right)=\left(P_{O R}^{\alpha}, P_{O R}, P_{O R}^{\beta}\right)
$$

where

$$
P_{O R}^{\alpha}=1-\prod_{i=1}^{n}\left[1-\left(m_{i}-\alpha_{i}\right)\right], P_{O R}=1-\prod_{i=1}^{n}\left[1-m_{i}\right], P_{O R}^{\beta}=1-\prod_{i=1}^{n}\left[1-\left(m_{i}+\beta_{i}\right)\right]
$$

In formula (11), if the probability of occurrence of $n$ events is an OR relationship, then the total probability $P_{O R}$ of $n$ events occurring at the same time is equal to the result of the probability of 1 minus the multiplication of $n$ events not occurring [20].

After the fuzzy operator of fault tree analysis is established, the fuzzy analysis of the fault tree can be carried out. Moreover, the resulting probability of the top event is a fuzzy number. With different confidence levels, different confidence intervals for the probability of the top event can be obtained.

\subsubsection{Interval Analysis of the Occurrence Probability of the Top Event}

According to the principle of fuzzy mathematics, the occurrence probability value of each basic event of the gas monitoring and prediction system is processed into a triangular fuzzy number [21], and the reference function is:

$$
\left\{\begin{aligned}
L\left(\frac{m-x}{a}\right)=\max \left(0, \frac{m-x}{\alpha}\right) & x \leq m, \alpha>0 \\
R\left(\frac{x-m}{\beta}\right)=\max \left(0, \frac{x-m}{\beta}\right) & x>m, \alpha>0
\end{aligned}\right.
$$

The membership function $A$ corresponding to the triangular fuzzy number is:

$$
\mu_{A(x)}=\left\{\begin{array}{rl}
0 & x<m-\alpha \\
1-\frac{m-x}{\alpha} & m-\alpha \leq x \leq m \\
1-\frac{x-m}{\beta} & m<x \leq m+\beta \\
0 & x>m+\beta
\end{array}\right.
$$


$A=(\alpha, m, \beta)$, where $m$ is the mean, $\alpha, \beta$ respectively are the upper and lower limits of the confidence interval. The distribution of $\alpha, \beta$ is larger, $A$ is more blurred. When $A$ is equal to $0, A$ is the non-fuzzy number. The $\lambda$ cut set of $A$ can be expressed as:

$$
\underset{\sim \lambda}{A}=[(m-\alpha)+\alpha \lambda,(m+\beta)-\beta \lambda]
$$

According to the principle of fuzzy mathematics, the probability value of each basic event in a gas monitoring and forecasting system is treated as a triangular fuzzy number [22].

Let $s_{1}$ and $s_{2}$ be the input events of the AND/OR gate, and s the output event, then, $\underline{F}_{s_{1}}$ and $\underline{F}_{s_{2}}$ represent the fuzzy failure probabilities of $s_{1}$ and $s_{2}$, respectively, as shown in Figure 2.

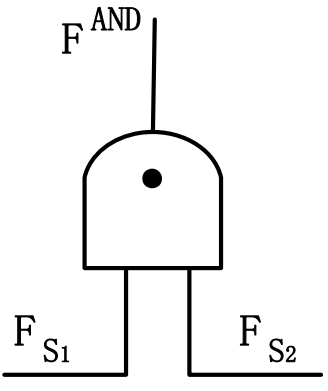

AND gate Structure

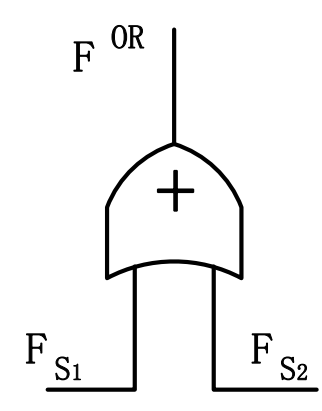

OR gate Structure

Figure 2. AND gate and OR gate structure chart.

Therefore, the fuzzy failure probability $\underline{\underline{F}}_{s}$ of the output event s of the AND gate/OR gate in the fault tree can be obtained by the following formula:

(1) AND gate structure

$$
\begin{aligned}
& \stackrel{F}{\sim}=\left[\left(m-\alpha_{1}\right)+\alpha_{1} \lambda,\left(m+\beta_{1}\right)-\beta_{1} \lambda\right], \underset{\sim}{\sim} \sim_{s_{2}}=\left[\left(m-\alpha_{2}\right)+\alpha_{2} \lambda,\left(m+\beta_{2}\right)-\beta_{2} \lambda\right] \\
{\underset{\sim}{\sim}}^{A N D} & =\underset{\sim}{F} F=\left[\left(m-\alpha_{1}\right)+\alpha_{1} \lambda,\left(m+\beta_{1}\right)-\beta_{1} \lambda\right]\left[\left(m-\alpha_{2}\right)+\alpha_{2} \lambda,\left(m+\beta_{2}\right)-\beta_{2} \lambda\right] \\
& =\left[\left[\left(m-\alpha_{1}\right)+\alpha_{1} \lambda\right]\left[\left(m-\alpha_{2}\right)+\alpha_{2} \lambda\right],\left[\left(m+\beta_{1}\right)-\beta_{1} \lambda\right]\left[\left(m+\beta_{2}\right)-\beta_{2} \lambda\right]\right]
\end{aligned}
$$

Formula (14) introduced the AND gate relationship between the output $\underline{F}_{S}$ with the inputs $\underline{F}_{s_{1}}$ and $\underline{F}_{S_{2}}$.

(2) OR gate structure

$$
\begin{aligned}
{\underset{\sim}{F}}^{O R} & =1-\left(\underset{\sim}{\sim} F_{s 1}\right)\left(1-F_{s 2}\right)=[1,1]-\prod_{1}^{2}\left\{[1,1]-\left[\left(m-\alpha_{i}\right)+\alpha_{i} \lambda,\left(m+\beta_{i}\right)-\beta_{i} \lambda\right]\right\} \\
& =\left[1-\prod_{1}^{2}\left[\left(m-\alpha_{1}\right)+\alpha_{1} \lambda\right], 1-\prod_{1}^{2}\left[\left(m+\beta_{1}\right)-\beta_{1} \lambda\right]\right]
\end{aligned}
$$

Formula (15) introduced the OR gate relationship between the output $\underline{F}_{S}$ with the inputs $\underline{F}_{s_{1}}$ and $\underline{F}_{s_{2}}$.

In this way, according to the structural function of the fault tree, the $\lambda$ cut interval of the occurrence probability of the top event can be calculated. By assigning different values to $\lambda$, the probability interval of the top event occurrence under different fuzzy degrees can be obtained [23]. 


\section{Reliability Analysis Process of Gas Monitoring System Based on Fuzzy-FTA}

\subsection{Failure Factor Analysis of Gas Monitoring System}

The main causes of hardware failure in coal mine gas monitoring systems are industrial computers and monitoring substation failures, sensor failures, communication line failures, power failures, etc. According to the analysis of data from mine gas monitoring systems, a number of accidents were taken as the top events, and their causes were analyzed [24].

In Table 1, B1-B5 are the intermediate events of the accident. B1-B4 are the hardware factors of the gas monitoring system failure, B5 is the human factor of the gas monitoring system failure. B1 is the monitoring computer failure, including the industrial computer host failure, display failure, and monitor substation failure. B2 is the monitoring system sensor failure, including the gas sensor failure, temperature sensor fault, wind speed sensor fault, power sensor failure, switch sensor failure, breaker failure, and PLC controller failure. B3 is monitoring system line failure, including the broken line, self-aging short circuit, and poor line contact. B4 is the monitoring system power supply and communication failure, including the abnormal power failure, high communication error rate, and short circuit to ground. B5 is the monitoring staff mistakes, including the lack of responsibility of the staff, system lack of spare parts, and insufficient maintenance technology.

Table 1. Fault tree event table of a gas monitoring system.

\begin{tabular}{|c|c|c|c|}
\hline Basic Event & Event Name & Basic Event & Event Name \\
\hline B1 & Industrial computer failure & $\mathrm{X7}$ & Power sensor failure \\
\hline $\mathrm{B} 2$ & Monitoring system sensor failure & $\mathrm{X} 8$ & Switch sensor failure \\
\hline B3 & Monitoring system line failure & X9 & Breaker failure \\
\hline B4 & $\begin{array}{l}\text { Monitoring system power supply } \\
\text { and communication failure }\end{array}$ & $\mathrm{X} 10$ & PLC controller failure \\
\hline B5 & Monitoring staff mistakes & $\mathrm{X} 11$ & Mechanically break the line \\
\hline $\mathrm{X} 1$ & Industrial computer host failure & $\mathrm{X} 12$ & Self-aging short circuit \\
\hline $\mathrm{X} 2$ & Display failure & $\mathrm{X} 13$ & Poor line contact \\
\hline X3 & Monitor substation failure & $\mathrm{X} 14$ & Abnormal power failure \\
\hline $\mathrm{X} 4$ & Gas sensor failure & $\mathrm{X} 15$ & High communication error rate \\
\hline X5 & Temperature sensor fault & $\mathrm{X} 16$ & Short circuit to ground \\
\hline X6 & Wind speed sensor fault & $\mathrm{X} 17$ & Lack of responsibility of the staff \\
\hline
\end{tabular}

\subsection{Establishing the Fault Tree Model}

The fault tree can be established by analyzing the aforementioned fault factors, as shown in Figure 3.

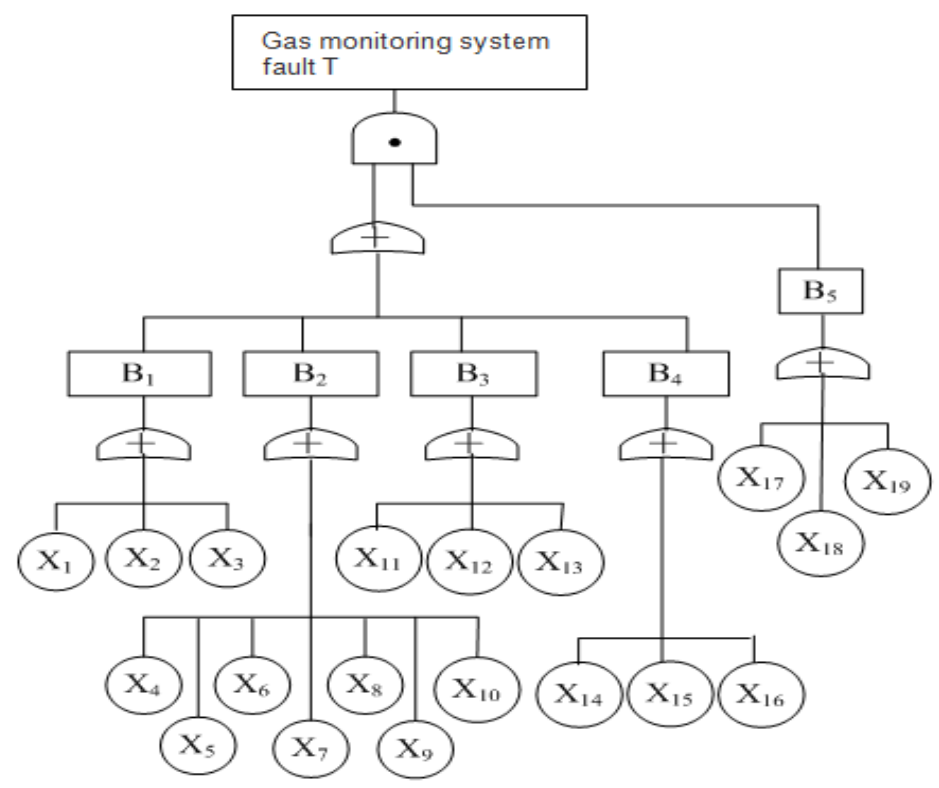

Figure 3. Fault tree of a gas monitoring system. 
When the gas monitoring system has a hardware failure and the staff fails to identify and deal with it in time, the gas monitoring system will malfunction [25].

Figure 3 shows that the number of OR gates is large, while that of AND gates is small, suggesting a potentially large failure rate of the system [22]. In fact, the OR gates produce an output for any basic event, whereas the AND gates produce an output only when all of the basic events occur simultaneously.

\subsection{Qualitative Analysis of Fault Tree}

As shown in Figure 3, the Boolean expression of its fault tree is listed, and its structural function expression is as follows:

$$
\begin{aligned}
T= & \left(B_{1}+B_{2}+B_{3}+B_{4}\right) \cdot B_{5} \\
= & {\left[\left(X_{1}+X_{2}+X_{3}\right)+\left(X_{4}+X_{5}+X_{6}+X_{7}+X_{8}+X_{9}+X_{10}\right)+\left(X_{11}+X_{12}+X_{13}\right)\right.} \\
& \left.+\left(X_{14}+X_{15}+X_{16}\right)\right] \cdot\left(X_{17}+X_{18}+X_{19}\right)
\end{aligned}
$$

The fault tree is transformed into a dual success tree by changing the OR gates into AND gates, and the AND gates into OR gates, as well as turning the events into their dual event. Then, the structural function of the success tree is written and subsequently simplified to obtain the structural function of the success tree represented by the minimum cut set. Two minimum path sets can be obtained as follows:

$$
\begin{gathered}
P_{1}=X_{1}+X_{2}+X_{3}+X_{4}+X_{5}+X_{6}+X_{7}+X_{8}+X_{9}+X_{10}+X_{11} \\
+X_{12}+X_{13}+X_{14}+X_{15}+X_{16} \\
P_{2}=X_{17}+X_{18}+X_{19}
\end{gathered}
$$

\subsection{Quantitative Analysis of Fault Tree}

In the framework of Fuzzy-FTA, and based on the theory of fuzzy sets, the L-R fuzzy numbers are used to represent the occurrence probability of basic events, based on which the fuzzy fault tree is analyzed and operated.

\subsubsection{Obtaining the Triangular Fuzzy Number of the Basic Events of the Fault Tree}

\begin{tabular}{|c|c|c|c|c|c|c|c|}
\hline $\begin{array}{l}\text { Basic } \\
\text { Event }\end{array}$ & Event Name & $\begin{array}{l}\text { Suggested } \\
\text { Value }\end{array}$ & $\begin{array}{c}\text { Order of } \\
\text { Magnitude }\end{array}$ & $\begin{array}{c}\text { Suggested } \\
\text { Order of } \\
\text { Magnitude }\end{array}$ & $\begin{array}{c}\text { Linguistic } \\
\text { Variable Value }\end{array}$ & $\begin{array}{c}\text { Linguistic } \\
\text { Variable Value }\end{array}$ & Remark \\
\hline $\mathrm{X} 1$ & Industrial computer host failure & & $10^{-5}$ & & & & \\
\hline $\mathrm{X} 2$ & Display failure & & $10^{-5}$ & & & & \\
\hline $\mathrm{X} 3$ & Monitor substation failure & & $10^{-5}$ & & & & \\
\hline $\mathrm{X} 4$ & Gas sensor failure & & $10^{-3}$ & & & & \\
\hline $\mathrm{X} 5$ & Temperature sensor fault & & $10^{-5}$ & & & & \\
\hline X6 & Wind speed sensor fault & & $10^{-5}$ & & & & \\
\hline $\mathrm{X} 7$ & Power sensor failure & & $10^{-5}$ & & & & \\
\hline $\mathrm{X} 8$ & Switch sensor failure & & $10^{-5}$ & & & & \\
\hline X9 & Breaker failure & & $10^{-5}$ & & & & \\
\hline $\mathrm{X} 10$ & PLC controller failure & & $10^{-6}$ & & & & \\
\hline $\mathrm{X} 11$ & Mechanically break the line & & $10^{-5}$ & & & & \\
\hline $\mathrm{X} 12$ & Self-aging short circuit & & $10^{-5}$ & & & & \\
\hline $\mathrm{X} 13$ & Poor line contact & & $10^{-4}$ & & & & \\
\hline X14 & Abnormal power failure & & $10^{-3}$ & & & & \\
\hline X15 & High communication error rate & & $10^{-8}$ & & & & \\
\hline X16 & Short circuit to ground & & $10^{-4}$ & & & & \\
\hline
\end{tabular}

(1) Obtain the triangular fuzzy number of the basic event of the fault tree

In order to obtain the probability of occurrence of 19 bottom events such as the coal mine gas monitoring system X1-X19, 10 on-site monitoring experts were selected to fill in the expert questionnaire. An expert questionnaire is shown in Table 2.

Table 2. Expert questionnaire on the probability of basic events. 
Table 2. Cont

\begin{tabular}{|c|c|c|c|c|c|c|c|}
\hline $\begin{array}{l}\text { Basic } \\
\text { Event }\end{array}$ & Event Name & $\begin{array}{l}\text { Suggested } \\
\text { Value }\end{array}$ & $\begin{array}{c}\text { Order of } \\
\text { Magnitude }\end{array}$ & $\begin{array}{c}\text { Suggested } \\
\text { Order of } \\
\text { Magnitude }\end{array}$ & $\begin{array}{c}\text { Linguistic } \\
\text { Variable Value }\end{array}$ & $\begin{array}{c}\text { Linguistic } \\
\text { Variable Value }\end{array}$ & Remark \\
\hline $\mathrm{X} 17$ & Lack of responsibility of the staff & & $10^{-4}$ & & & & \\
\hline X18 & System lacks spare parts & & $10^{-2}$ & & & & \\
\hline X19 & $\begin{array}{l}\text { Insufficient maintenance } \\
\text { technology }\end{array}$ & & $10^{-2}$ & & & & \\
\hline
\end{tabular}

Remark: (1) "Guistic variable value" column: 1: Impossible, 3: Seldom, 5: Occasional, 7: Probable, 9: Frequently. (2) "Inguistic variable value" column: 2: Surely, 4: Nearly, 6: This may be a little better, 8: It is hard to determine. (3) "Order of magnitude" column, the quantity value comes from the relevant data. If you think it is inappropriate, please fill in the value you think is suitable in the back column.

Through the feedback of the 10 expert questionnaires from the field, the MATLAB software was used to program the arithmetic mean of the X1-X19 probability interval. In addition, the average value of the probability interval and the left and right distribution of the occurrence of each bottom event were calculated, as shown in Table 3.

Table 3. Probability of occurrence of the fault tree event table.

\begin{tabular}{|c|c|c|c|}
\hline Basic Event & Event Name & Graduate & Probability of Occurrence \\
\hline $\mathrm{X} 1$ & $\begin{array}{l}\text { Industrial computer host } \\
\text { failure }\end{array}$ & $q_{1}$ & {$[4.60+0.52 \lambda, 6.52-0.52 \lambda] \times 10^{-5}$} \\
\hline $\mathrm{X} 2$ & Display failure & $q_{2}$ & {$[4.96+0.44 \lambda, 6.44-0.44 \lambda] \times 10^{-5}$} \\
\hline $\mathrm{X} 3$ & Monitor substation failure & $q_{3}$ & {$[2.36+0.24 \lambda, 2.84-0.24 \lambda] \times 10^{-5}$} \\
\hline $\mathrm{X} 4$ & Gas sensor failure & $q_{4}$ & {$[4.08+0.52 \lambda, 5.12-0.52 \lambda] \times 10^{-3}$} \\
\hline X5 & Temperature sensor fault & $q_{5}$ & {$[2.92+0.28 \lambda, 3.48-0.28 \lambda] \times 10^{-5}$} \\
\hline X6 & Wind speed sensor fault & $q_{6}$ & {$[5.20+0.60 \lambda, 6.40-0.60 \lambda] \times 10^{-5}$} \\
\hline $\mathrm{X} 7$ & Power sensor failure & $q_{7}$ & {$[3.88+0.32 \lambda, 4.52-0.32 \lambda] \times 10^{-5}$} \\
\hline $\mathrm{X} 8$ & Switch sensor failure & $q_{8}$ & {$[4.86+0.54 \lambda, 5.94-0.54 \lambda] \times 10^{-5}$} \\
\hline X9 & Breaker failure & $q_{9}$ & {$[4.56+0.64 \lambda, 5.84-0.64 \lambda] \times 10^{-5}$} \\
\hline $\mathrm{X} 10$ & PLC controller failure & $q_{10}$ & {$[4.36+0.24 \lambda, 4.84-0.24 \lambda] \times 10^{-6}$} \\
\hline $\mathrm{X} 11$ & Mechanically break the line & $q_{11}$ & {$[1.88+0.32 \lambda, 2.52-0.32 \lambda] \times 10^{-5}$} \\
\hline $\mathrm{X} 12$ & Self-aging short circuit & $q_{12}$ & {$[4.44+0.56 \lambda, 5.56-0.56 \lambda] \times 10^{-5}$} \\
\hline $\mathrm{X} 13$ & Poor line contact & $q_{13}$ & {$[3.80+0.40 \lambda, 4.60-0.40 \lambda] \times 10^{-5}$} \\
\hline $\mathrm{X} 14$ & Abnormal power failure & $q_{14}$ & {$[3.10+0.30 \lambda, 3.70-0.30 \lambda] \times 10^{-3}$} \\
\hline $\mathrm{X} 15$ & High communication error rate & $q_{15}$ & {$[3.00+0.40 \lambda, 3.80-0.40 \lambda] \times 10^{-8}$} \\
\hline $\mathrm{X} 16$ & Short circuit to ground & $q_{16}$ & {$[3.78+0.42 \lambda, 4.62-0.42 \lambda] \times 10^{-4}$} \\
\hline $\mathrm{X} 17$ & $\begin{array}{l}\text { Lack of responsibility of the } \\
\text { staff }\end{array}$ & $q_{17}$ & {$[4.48+0.52 \lambda, 5.52-0.52 \lambda] \times 10^{-4}$} \\
\hline $\mathrm{X} 18$ & System lacks spare parts & $q_{18}$ & {$[2.70+0.30 \lambda, 3.30-0.30 \lambda] \times 10^{-2}$} \\
\hline $\mathrm{X} 19$ & $\begin{array}{l}\text { Insufficient maintenance } \\
\text { technology }\end{array}$ & $q_{19}$ & {$[3.68+0.32 \lambda, 4.32-0.32 \lambda] \times 10^{-3}$} \\
\hline
\end{tabular}

\subsubsection{Calculation of the Fuzzy Probability of the Top Event}

The $\lambda$ cut set is shown in Table 1 according to the triangular fuzzy probability of each basic event. After obtaining the cut-off set of each basic event, the probability of the top event is calculated using Equation [26]. The probability of the top event is calculated as follows:

$$
g=\left\{[1,1]-\prod_{i=1}^{16}\left([1,1]-q_{i}\right)\right\} \times\left\{[1,1]-\left([1,1]-q_{17}\right)\left([1,1]-q_{18}\right)\left([1,1]-q_{19}\right)\right\}
$$

The fuzzy probability of the top event is obtained by evaluating the structural function of the fault tree. Moreover, the high-order items ignored in the calculation process are obtained. The $\lambda$ cut set form of the occurrence probability of the top event is calculated as follows:

$$
T=[0.000095+0.000020 \lambda, 0.000135-0.000022 \lambda]
$$


The probability intervals of the top event according to the different values of $\lambda$ are presented in Table 4.

Table 4. Top event probability intervals according to the value of $\lambda$.

\begin{tabular}{cccc}
\hline$\lambda$ & $\begin{array}{c}\text { Top Event Occurs } \\
\text { Probability Interval }\end{array}$ & $\lambda$ & $\begin{array}{c}\text { Top Event Occurs } \\
\text { Probability Interval }\end{array}$ \\
\hline 0 & {$[0.000095,0.000135]$} & 0.6 & {$[0.000107,0.000123]$} \\
0.1 & {$[0.000097,0.000133]$} & 0.7 & {$[0.000109,0.000121]$} \\
0.2 & {$[0.000099,0.000131]$} & 0.8 & {$[0.000111,0.000119]$} \\
0.3 & {$[0.000101,0.000129]$} & 0.9 & {$[0.000113,0.000117]$} \\
0.4 & {$[0.000103,0.000127]$} & 1 & {$[0.000115]$} \\
0.5 & {$[0.000105,0.000125]$} & & \\
\hline
\end{tabular}

It can be seen from Table 4 that when $\lambda=1$, the fuzzy degree of the occurrence probability of the top event is the smallest, and its occurrence probability is approximately 0.000115 . When $\lambda=0$, the probability of occurrence of the top event is the fuzziest, and its probability interval is [0.000095, 0.000135], which shows that the system has a better reliability performance than the traditional fault tree.

\subsection{Structural Importance Analysis}

The structural importance analysis is used to analyze the contribution of each basic event to the occurrence of the top event from the fault tree structure. This involves analyzing the influence of each basic event on the occurrence of the top event without considering the occurrence probability of the basic event or assuming that the occurrence of each basic event is almost equal. The greater the importance of the basic event structure, the greater its influence on the top event, and vice versa. There are many methods for analyzing the importance of a structure. Here, the permutation method is used, and the solution results are arranged as follows:

$\mathrm{I} 17=\mathrm{I} 18=\mathrm{I} 19>\mathrm{I} 1=\mathrm{I} 2=\mathrm{I} 3=\mathrm{I} 4=\mathrm{I} 5=\mathrm{I} 6=\mathrm{I} 7=\mathrm{I} 8=\mathrm{I} 9=\mathrm{I} 10=\mathrm{I} 11=\mathrm{I} 12=\mathrm{I} 13=\mathrm{I} 14=\mathrm{I} 15=\mathrm{I} 16$

\subsection{Analysis of Fault Tree Results}

By analyzing the results of the fault tree, the following conclusions can be drawn.

(1) The main reasons for the hardware failure of a coal mine gas monitoring system are associated with the control system hardware failure as follows: (i) The factors that cause the failure of the industrial computer include the industrial computer motherboard failure, display failure, and accessory failure; (ii) the factors that cause sensor failures include the gas sensor failure, temperature sensor failure, wind speed sensor failure, power sensor failure, switch sensor failure, power-off device failure, and PLC controller failure; (iii) the factors that cause communication line failures include the mechanical pull and open circuit, self-aging short circuit, and poor contact; (iv) the factors that cause power outages include the abnormal power outages, power line open circuits, and power line short circuits; (v) the factors that cause poor maintenance are insufficient sense of responsibility, lack of spare parts, and insufficient maintenance technology. By analyzing the fault tree structure, we can see that the number of logic OR gates is far greater than the logic AND gates, making the probability of accidents very high.

(2) Through the qualitative analysis, it can be seen from the minimum path set that there are only four ways to prevent the occurrence of T events. Coal mine gas monitoring system accidents are prone to occur, and there are a few ways to prevent accidents.

(3) There are 19 basic events that lead to accidents. However, since the current hardware equipment has a long mean time between failures (MTBF), the probability of accidents is very low. The accident probability of other basic events related to human operations 
is generally higher. Therefore, in the failure of coal mine gas monitoring systems, human factors are the main cause of failure [27].

(4) From the analysis of structural importance, it can be seen that the three basic events of insufficient sense of responsibility, lack of spare parts, and insufficient maintenance technology occupy the most important weight, and therefore are the top priority for accident prevention.

(5) The quantitative analysis shows that the probability of failure of the coal mine gas monitoring system under normal conditions is approximately $0.011 \%$, which is highly dangerous.

In summary, the management of coal mine gas monitoring systems should be based on human factors, such as the awareness of the job responsibilities of the monitoring personnel, the training and supervision of the monitoring personnel, and the technical ability to maintain the system should be strengthened. This reduces the failure of the coal mine gas monitoring system as much as possible, thereby reducing mine gas outburst accidents.

\subsection{Comparison of FTA and Fuzzy-FTA}

In FTA, the probability of occurrence of various accidents X1-X19 at the gas monitoring system site comes from the expert questionnaire filled out by the on-site monitoring personnel. Each probability data required to fill in the expert questionnaire is specific and accurate, but this requirement is difficult for the on-site monitoring personnel, who are more inclined to fill in a probability interval for failure [28]. In Fuzzy-FTA, they only need to fill in the probability interval of failure.

In the process of data calculation, FTA is calculated according to simple rules, and the result obtained is a specific probability value. As an example, take the data in Table 1 , then take $\lambda=1$, and take the probability of occurrence of various accidents X1-X19 as the intermediate value, the probability of occurrence of the top event is 0.00011 . The Fuzzy-FTA is calculated according to the fuzzy mathematics rule, taking $\lambda=0.5$, we can get the probability of the top event in the interval: [0.000105, 0.000125]. From this, we can know that the minimum probability of the top event is 0.000105 , the maximum probability of the top event is 0.000125 , and the high probability of the occurrence of the event belongs to the interval: [0.000105, 0.000125].

From the comparison of FTA and Fuzzy-FTA, it can be seen that Fuzzy-FTA can more easily obtain data close to the actual on-site, and obtain calculation results that are more in line with the actual on-site. However, compared with FTA, Fuzzy-FTA requires a large amount of data and more complex calculations [29].

\section{Conclusions}

The Fuzzy-FTA method represents an improvement over the conventional FTA, as it can accurately estimate the probability of each basic event. Through the fuzzy interpretation of data obtained by interviewing the on-site monitoring personnel with a rich management experience, the probability interval of the hardware reliability of a gas monitoring system based on different confidence levels can be obtained. It should be pointed out that the use of fuzzy mathematics to describe the probability of event discovery can not only reduce the difficulty of obtaining the accurate value of the probability of large and complex system events. At the same time, it can also combine field data with the experience of engineers and technicians. This method has greater advantages in flexibility and adaptability than the traditional FTA. In the future, the difficulty of big data calculation of the Fuzzy-FTA method can be reduced by software programming, in order for the method to be applied to more scenarios.

Author Contributions: Investigation, M.Y.; writing—original draft preparation, J.X.; writing—review and editing, S.L. All authors have read and agreed to the published version of the manuscript.

Funding: This research received no external funding. 
Institutional Review Board Statement: Not applicable.

Informed Consent Statement: Not applicable.

Acknowledgments: The authors would like to thank the 10 experts at the coal mine site who carefully filled out our questionnaire.

Conflicts of Interest: The funders had no role in the design of the study; in the collection, analyses, or interpretation of data; in the writing of the manuscript, or in the decision to publish the results.

\section{References}

1. Dong, J.-X.; Cheng, L. Evaluation method of coal mine mode gas control mode based on analytic hierarchy process. Eng. Trans. 2018, 71, 319-324.

2. Wang, W.; Wang, H.-P.; Zhang, B.; Wang, S.-X. Coal and gas outburst prediction model based on extension theory and its application. Process. Saf. Environ. Prot. 2021, 154, 329-337. [CrossRef]

3. Li, D.; Cao, Q.-G.; Wang, J.-J.; Mi, X. Application of integrated method of hazop-ahp and fuzzy comprehensive evaluation in coal mine gas explosion accident. Earth Environ. Sci. 2021, 692, 131-136. [CrossRef]

4. Tanaka, H.; Fan, L.-T.; Lai, F.-S.; Toguchi, K. Fault-tree analysis by fuzzy probability. Trans. Reliab. 1983, 32, 453-457. [CrossRef]

5. Huang, H.-Z.; Tong, X.; Ming, J.; Zuo, M.-J. Posbist fault tree analysis of coherent. systems. Reliab. Eng. Syst. Saf. 2004, 84, 141-148. [CrossRef]

6. Li, Q.; Lu, T.-J.; Li, N.-P. Fuzzy fault tree analysis and application of triangular fuzzy numbers. J. China Univ. Min. Technol. 2000, 1, 56-59.

7. Liu, P.-Y.; Wu, M.-D. Fuzzy Theory and Its Application; National University of Defense Technology Press: Beijing, China, 1998; pp. 124-134.

8. Zhang, Y.-Q. Failure Mode Analysis of Waterjet Hydraulic System Based on Fuzzy-FTA; Dalian Maritime University: Dalian, China, 2010; pp. 145-164.

9. Liu, S.-H.; Lin, S.-F.; Jiang, X.-X. Research on the reliability of steering gear hydraulic system based on fuzzy fault tree analysis. Ship Eng. 2008, 30, 27-29.

10. Singer, D.-A. Fuzzy set approach to fault tree and reliability analysis. Fuzzy Sets Syst. 1990, 34, 145-155. [CrossRef]

11. Sawyer, J.-P. Fault tree analysis of mechanical systems. Micro-Electron. Reliab. 1994, 54, 653-667. [CrossRef]

12. Misra, K.-B.; Feber, G.-G. A new method for fuzzy fault tree analysis. Micro-Electron. Reliab. 1989, 29, 195-216. [CrossRef]

13. Kenarangui, R. Event-tree analysis by fuzzy probability. IEEE Trans. Reliab. 1991, 40, 120-124. [CrossRef]

14. Furuta, H.; Shiraishi, N. Fuzzy importance in fault tree analysis. Fuzzy Sets Syst. 1984, 12, 205-213. [CrossRef]

15. Xu, J.-T.; Li, S.-G.; Huang, J.-X. Safety research on mine gas monitoring system based on FTA. Prog. Saf. Manag. Res. Pract. 2009, 479, 2090-2094.

16. Li, X. A new study of fuzzy fault tree. Electron. Prod. Reliab. Environ. Test. 2007, 25, 27-30.

17. Long, Z.-Q.; Lu, Z.-G.; Chang, W.-S. Fault diagnosis to suspension system of maglev train based on fuzzy fault tree. Control Decis. 2004, 19, 140-142.

18. Duan, B.; He, Z.-H. Fuzzy fault tree reliability analysis of the three gorges ship lock control system. Int. J. Hydroelectr. Energy 2002, 20, 58-61.

19. Shi, S.-L.; Jiang, B.-Y.; Meng, X.-R.; Yang, L. Fuzzy fault tree analysis for gas explosion of coal mining and headingfaces in underground coal mines. Adv. Mech. Eng. 2018, 10, 12-16. [CrossRef]

20. Wang, Y.-Q.; Cheng, G.X.; Zhao, Z.-H. Fuzzy fault tree analysis of reforming furnace. J. Xi'an Jiaotong Univ. 2010, 44, 86-89.

21. Adam, S.M.; Dorota, S. Fuzzy logic approach to calculation of thermal hazard distances in process industries. Process. Saf. Environ. Prot. 2014, 92, 338-345.

22. Wang, H.-T.; Li, J.; Wang, D.-M.; Huang, Z.-H. A novel method of fuzzy fault tree analysis combined with VB program to identify and assess the risk of coal dust explosions. PLoS ONE 2017, 12, e0182453. [CrossRef]

23. Li, X.-Y.; Qi, J.-P. Reliability analysis of the pantograph system based on the T-S fuzzy FTA. J. Saf. Environ. 2018, $18,33-38$.

24. Chen, P.-F.; Wu, F.; He, P.-L.; Wen, X.-W. Fault diagnosis method of chamber cover mechanism based on T-S fuzzy FTA and simulation. Aeroengine 2018, 44, 97-102.

25. Adam, S.M.; Dorota, S. Fuzzy logic approach for identifying representative accident scenarios. J. Loss Prev. Process. Ind. 2018, 56, $414-423$.

26. Shi, S.-L.; Jiang, B.-Y.; Meng, X.-R. Assessment of gas and dust explosion in coal mines by means of fuzzy fault tree analysis. Int. J. Min. Sci. Technol. 2018, 28, 991-998. [CrossRef]

27. Zhang, Y.-D.; Qing, L.; Pu, W.; Zhang, S.-G.; Niu, B. Safety analysis of waste heat boiler based on FMECA and fuzzy TA. Saf. Prod. Sci. Technol. China 2015, 11, 164-170.

28. Zheng, W. Fuzzy FTA for river-traversing oil pipeline. J. Oil Gas. Technol. 2009, 31, 153-156.

29. Li, W.-F.; You, Q.-H.; Liao, Q.; Xu, M.-J. Research on remote fault diagnosis method based on T-S fuzzy FTA. Control Eng. China 2018, 9, 1703-1706. 